\title{
Alemtuzumab long-term immunologic effect
}

\author{
Treg suppressor function increases up to 24 months \\ OPEN
}

Stefania De Mercanti,

MD*

Simona Rolla, BS, PhD*

Angele Cucci, BS, PhD

Valentina Bardina, BS

Eleonora Cocco, MD

Anton Vladic, MD, PhD

Silva Soldo-Butkovic,

$\mathrm{MD}, \mathrm{PhD}$

Mario Habek, MD, PhD

Ivan Adamec, $\mathrm{MD}, \mathrm{PhD}$

Dana Horakova, MD,

$\mathrm{PhD}$

Pietro Annovazzi, MD

Francesco Novelli, BS,

$\mathrm{PhD} \ddagger$

Luca Durelli, MD

Marinella Clerico, MD, $\mathrm{PhD \ddagger}$

Correspondence to

Dr. Durelli:

luca.durelli@unito.it

\section{Supplemental data} at Neurology.org/nn

\section{ABSTRACT}

Objective: To analyze changes in T-helper (Th) subsets, T-regulatory (Treg) cell percentages and function, and mRNA levels of immunologically relevant molecules during a 24-month follow-up after alemtuzumab treatment in patients with relapsing-remitting multiple sclerosis (RRMS).

Methods: Multicenter follow-up of 29 alemtuzumab-treated patients with RRMS in the Comparison of Alemtuzumab and Rebif Efficacy in Multiple Sclerosis (CARE-MS) I and CARE-MS II trials. Peripheral blood (PB) samples were obtained at months $0,6,12,18$, and 24. We evaluated (1) mRNA levels of 26 immunologic molecules (cytokines, chemokines, chemokine receptors, and transcriptional factors); (2) Th1, Th17, and Treg cell percentages; and (3) myelin basic protein (MBP)-specific Treg suppressor activity.

Results: We observed 12 relapses in 9 patients. mRNA levels of the anti-inflammatory cytokines interleukin (IL)-10, IL-27, and transforming growth factor- $\beta$ persistently increased whereas those of proinflammatory molecules related to the Th1 or Th17 subsets persistently decreased after alemtuzumab administration throughout the follow-up period. PB CD4+ cell percentage remained significantly lower than baseline while that of Th1 and Th17 cells did not significantly change. A significant increase in Treg cell percentage was observed at month 24 and was accompanied by an increase in Treg cell suppressive activity against MBP-specific Th1 and Th17 cells.

Conclusions: The long-lasting therapeutic benefit of alemtuzumab in RRMS may involve a shift in the cytokine balance towards inhibition of inflammation associated with a reconstitution of the PB CD4+ T-cell subsets that includes expansion of Treg cells with increased suppressive function. Neurol Neuroimmunol Neuroinflamm 2016;3:e194; doi: 10.1212/NXI.0000000000000194

\section{GLOSSARY}

BBB = blood-brain barrier; CARE-MS = Comparison of Alemtuzumab and Rebif Efficacy in Multiple Sclerosis; CCL = C-C motif ligand; $\mathbf{C C R}=\mathrm{C}-\mathrm{C}$ chemokine receptor; $\mathbf{C X C L}=\mathrm{C}-\mathrm{X}-\mathrm{C}$ motif ligand; $\mathbf{C X C R}=\mathrm{C}-\mathrm{X}-\mathrm{C}$ chemokine receptor; EDSS = Expanded Disability Status Scale; ELISPOT = enzyme-linked immunospot; FACS = fluorescence-activated cell sorting; FoxP3 = forkhead box P3; IFN = interferon; IL = interleukin; $\mathbf{m A b}=$ monoclonal antibodies; $\mathbf{M B P}=$ myelin basic protein; $\mathbf{M S}=$ multiple sclerosis; PB = peripheral blood; PBMC = peripheral blood mononuclear cells; PPD = purified protein derivative of tuberculin; RORC = retinoid-related orphan receptor $\gamma ; \mathbf{R R}=$ relapsing-remitting; Tbet $=$ T-box expressed in T cells; TGF = transforming growth factor; Th = T-helper; TNF = tumor necrosis factor; Treg $=$ T-regulatory cells; VLA $=$ very late antigen.

Alemtuzumab is a humanized monoclonal antibody that targets the CD52 antigen, expressed mainly on the surface of $\mathrm{T}$ and $\mathrm{B}$ lymphocytes and less on natural killer cells, monocytes, and dendritic cells. ${ }^{1}$ Besides its use in fludarabine-resistant B-cell chronic lymphocytic leukemia, ${ }^{2}$ alemtuzumab was tested in 2 phase III trials (Comparison of Alemtuzumab and Rebif

*These authors contributed equally to this work.

From the Division of Neurology (S.D.M., S.R., A.C., L.D., M.C.) and the Department of Clinical and Biological Sciences (S.D.M., A.C., L.D., M.C.), University of Torino, San Luigi Gonzaga University Hospital, Orbassano; Center for Experimental Research and Medical Studies (CERMS) (S.R., V.B., F.N.), Azienda Ospedaliera Città della Salute e della Scienza di Torino; Department of Molecular Biotechnology and Health Sciences (V.B., F.N.), Università degli Studi di Torino; Multiple Sclerosis Center (E.C.), Department of Public Health, Clinical and Molecular Medicine, University of Cagliari, Italy; Department of Neurology (A.V., S.S.-B.), Clinical Hospital Sveti Duh Zagreb; Medical Faculty University (A.V., S.S.-B.), J.J. Strossmayer Osijek; Department of Neurology (M.H., I.A.), Referral Center for Demyelinating Diseases of the Central Nervous System, University Hospital Center Zagreb, Croatia; Department of Neurology and Center of Clinical Neuroscience (D.H.), Charles University in Prague, First Faculty of Medicine and General University Hospital, Czech Republic; and Multiple Sclerosis Study Center (P.A.), AO S. Antonio Abate, Gallarate (VA), Italy.

Funding information and disclosures are provided at the end of the article. Go to Neurology.org/nn for full disclosure forms. The Article Processing Charge was paid by Dipartimento di Scienze Cliniche e Biologiche-Torino University.

¥These authors share senior authorship.

Coinvestigators are listed on the Neurology ${ }^{\circledR}$ Web site at Neurology.org/nn.

This is an open access article distributed under the terms of the Creative Commons Attribution-NonCommercial-NoDerivatives License 4.0 (CC BYNC-ND), which permits downloading and sharing the work provided it is properly cited. The work cannot be changed in any way or used commercially. 
Efficacy in Multiple Sclerosis [CARE-MS] $\mathrm{I}^{3}$ and CARE-MS $\mathrm{II}^{4}$ ) in relapsing-remitting (RR) multiple sclerosis (MS). These 2 trials were designed to test the superiority of alemtuzumab vs interferon (IFN)- $\beta$-1a, $44 \mathrm{mcg}$ subcutaneously, 3 times a week. Compared with IFN- $\beta$, alemtuzumab significantly reduced relapse rate by $49 \%{ }^{3}$ to $55 \%{ }^{4}$ and the risk of sustained accumulation of disability over 6 months by $42 \%{ }^{4}$

A single therapeutic course of alemtuzumab induces severe $\mathrm{T}$ - and B-cell depletion, with lymphocyte repopulation occurring over several months, ${ }^{5}$ and an increase of the percentage of T-regulatory cells (Treg).

T-helper (Th) subsets are involved in MS pathology, and brain MS lesions are enriched in Th1 and Th17 cells. ${ }^{6}$ Th17 and Th1/17 cells (an intermediate subset producing interleukin [IL]-17 and IFN- $\gamma^{7}$ ) are increased in the peripheral blood $(\mathrm{PB})$ and CSF at the time of a new relapse ${ }^{8}$ and cross the blood-brain barrier (BBB) more easily than Th1 cells. ${ }^{9}$ Some reports have examined $^{10,11}$ the CD19, CD4, and CD8 subsets and related cytokine changes in a few patients treated with alemtuzumab. No studies have evaluated Treg function in alemtuzumab-treated patients with MS. We organized a multicenter 24-month study to analyze the changes in Th subsets, Treg proportion and function, and mRNA levels of cytokines and other immunologically related molecules during phase III alemtuzumab trials. ${ }^{3,4}$ The long-term follow-up of immune system reconstitution together with clinical and radiologic data could provide practical tools to define the timing of repeated alemtuzumab courses.

METHODS Patients and clinical study design. Twentynine patients with RRMS ${ }^{12}$ participating in CARE-MS $\mathrm{I}^{3}$ and $\mathrm{II}^{4}$ trials in 6 European MS centers entered this study and were evaluated at baseline and for 24 months after alemtuzumab treatment. Inclusion and exclusion criteria were described in the original articles. ${ }^{3,4}$ Patients were treated with $12 \mathrm{mg} / \mathrm{d}$ IV alemtuzumab in 2 annual courses ( 5 administrations at month 0 and 3 administrations at month 12). Patients' demographic and clinical characteristics are reported in the table. Neurologic assessments, performed by blinded investigators, were done at baseline and repeated every month or in case of relapses. Blood samples were taken at baseline (before first alemtuzumab course) and at months 6,12 (before second alemtuzumab course), 18, and 24. At each time point, blood cell count, coagulation,
Table

Demographic data

\begin{tabular}{ll} 
& Values \\
Sex, F/M & $17 / 12$ \\
\hline Age at baseline, $y$ & $34 \pm 8.7$ \\
Age at onset, $y$ & $28.2 \pm 9.2$ \\
EDSS at baseline & $2.5 \pm 1.1$ \\
Disease duration, $y$ & $5 \pm 3.5$ \\
No. relapses in the 2 y before baseline & $1.7 \pm 1.1$
\end{tabular}

Abbreviation: EDSS $=$ Expanded Disability Status Scale. Values are $\mathrm{n}$ or mean $\pm \mathrm{SD}$.

thyroid, liver, and kidney function were analyzed in a central facility. Fresh blood was collected in heparin-treated vacutainers and immediately sent to a single coordinating center located at the University of Torino for immunologic testing. All samples were received and processed within 48 hours from the blood withdrawal.

Standard protocol approvals, registrations, and patient consents. The institutional review board of the participating centers approved the study and all subjects gave written informed consent (protocol number Bio2009001).

Cytokine mRNA analysis. Aliquots $(0.5 \mathrm{~mL}$ each) of blood were mixed with $1.3 \mathrm{~mL}$ RNAlater (Ambion, Life Technologies, Carlsbad, CA) immediately after arrival at the coordinating center and stored at $-80^{\circ} \mathrm{C}$. To determine mRNA levels, samples were treated as previously described ${ }^{13}$ : RNA was extracted with the RiboPure Blood Kit (Ambion) and cDNA obtained with the high-capacity cDNA reverse transcription kit (Applied Biosystems, Life Technologies, Monza, Italy). ${ }^{13}$

We assessed the mRNA levels of the following 26 immunologically relevant molecules whose function in MS has been documented by using TaqMan low-density arrays (Applied Biosystems $7900 \mathrm{HT}$ real-time PCR system $)^{13}$ : molecules with proinflammatory function including IL-1 $\beta,{ }^{14}$ IL- $2,{ }^{15}$ IL- $6,{ }^{16}$ IL-12, ${ }^{17}$ IL-17A, ${ }^{18}$ IL-17F, ${ }^{19}$ IL-21,,${ }^{20}$ IL-22, ${ }^{21}$ IL-23, ${ }^{22}$ IL-26, ${ }^{23}$ IFN- $\gamma,{ }^{14}$ T-box expressed in $\mathrm{T}$ cells (Tbet), ${ }^{23}$ retinoid-related orphan receptor $\gamma$ (RORC), ${ }^{24}$ tumor necrosis factor- $\alpha$ (TNF- $\alpha$ ), ${ }^{25}$ C-C chemokine receptor type 3 (CCR3), ${ }^{26}$ CCR $4,{ }^{27}$ CCR $5,{ }^{26}$ CCR6, ${ }^{28}$ C-X-C chemokine receptor type 3 (CXCR3), ${ }^{29}$ C-X-C motif ligand 10 (CXCL10), ${ }^{29}$ C-C motif ligand 20 $\left(\right.$ CCL20), ${ }^{30}$ and very late antigen 4 (VLA4) ${ }^{31}$; and molecules with anti-inflammatory function, including IL-10, ${ }^{32}$ IL-27, ${ }^{33}$ transforming growth factor- $\beta$ (TGF- $\beta$ ), ${ }^{32}$ and forkhead box P3 (FoxP3). ${ }^{34}$ Glyceraldehyde-3 phosphate dehydrogenase served as the housekeeping gene for normalization. The relative expression of each gene was calculated using the comparative threshold cycle method as directed by the manufacturer (User Bulletin No. 2, Applied Biosystems) and expressed in arbitrary units as previously described in detail. ${ }^{13}$

Flow cytometry (fluorescence-activated cell sorting [FACS]). PB mononuclear cells (PBMC) were isolated by density gradient centrifugation from heparinized venous blood. PBMC were stained for Treg cells with anti-CD4, anti-CD25, and anti-CD127 monoclonal antibodies (mAb) (Biolegend, San Diego, CA) on the cell surface. For detection of the transcriptional factor FoxP3, cells were fixed with fixation and permeabilization buffers (eBioscience, San Diego, CA) and were then stained with anti-FoxP3 mAb (eBioscience). The 
expression of IL-17 and IFN- $\gamma$ was analyzed by intracellular cytokine staining. ${ }^{8,20}$ PBMC were cultured in Iscove's modified Dulbecco's medium (BioWhittaker, Walkersville, MD) supplemented with $10 \%$ fetal bovine serum (Invitrogen, Carlsbad, CA) and stimulated for 5 hours with Phorbol 12-myristate 13-acetate PMA $(50 \mathrm{ng} / \mathrm{mL})$ and ionomycin $(500$ $\mathrm{ng} / \mathrm{mL})$ in the presence of brefeldin A $(10 \mu \mathrm{g} / \mathrm{mL}$, Sigma-Aldrich, St. Louis, MO). Cells were first stained for the surface antigen CD4 (Biolegend) and then fixed with $4 \%$ paraformaldehyde, permeabilized with $0.5 \%$ saponin, followed by intracellular staining with anti-IL-17 and anti-IFN- $\gamma$ mAbs (Biolegend). Stained PBMC were acquired on a FACSCalibur (BD Biosciences, San Jose, CA) and analyzed with FlowJo software (Ashland, OR).

Enzyme-linked immunospot (ELISPOT) assay. Antigenspecific IFN- $\gamma$ and IL-17-producing cells and antigen-specific suppressor activity of Treg cells were assessed by ELISPOT (eBioscience) at months 0,12 , and 24. To remove Treg cells from PBMC (PBMC ${ }^{\mathrm{CD} 25-}$ ), the $\mathrm{CD} 25+$ fraction was depleted using immunomagnetic beads (Miltenyi Biotec, Bergisch Gladbach, Germany). $1 \times 10^{5}$ Total PBMC or PBMC ${ }^{\mathrm{CD} 25-}$ were seeded in 96-well ELISPOT assay plates (Millipore, Darmstadt, Germany) in triplicate and incubated for 48 hours at $37^{\circ} \mathrm{C}$ either with myelin basic protein (MBP, $40 \mu \mathrm{g} / \mathrm{mL}$, Sigma-Aldrich) or with purified protein derivative of tuberculin (PPD, $40 \mu \mathrm{g} / \mathrm{mL}$, Sigma-Aldrich) as control. ${ }^{8}$ IFN- $\boldsymbol{\gamma}$-specific or IL-17-specific spots were counted by computer-assisted image analysis (Transtec 1300 ELISpot Reader; AMI Bioline, Buttigliera Alta, Italy). The number of IFN- $\gamma$ or IL-17 spots produced spontaneously was subtracted from the number of spots produced by antigen-stimulated cells to obtain the number of IFN- $\gamma$ and IL-17 antigen-specific spots in the PBMC or in the $\mathrm{PBMC}^{\mathrm{CD} 25-}$, as previously described. ${ }^{8}$

Statistical analysis. Statistical analysis was performed using Prism 5.0 GraphPad (La Jolla, CA) software. For the longitudinal follow-up, statistical significance was calculated with respect to baseline by using one-way analysis of variance for repeated measures followed by Bonferroni multiple comparison posttest. ${ }^{8,20}$ Pearson $t$ test was used to analyze the differences between groups. $p$ Values $\leq 0.05$ were considered statistically significant.

RESULTS Clinical results. A cohort of 29 patients with RRMS was followed for 24 months during the CAREMS $\mathrm{I}^{3}$ and $\mathrm{II}^{4}$ trials. Three patients did not receive the second alemtuzumab course, 2 owing to early study dropout and another owing to the occurrence of thrombocytopenia. The most common adverse events were cutaneous rashes. Thrombocytopenia and isolated neutropenia occurred in 2 patients, respectively, 4 and 6 months after the first course. A few infections occurred: herpes labialis (2 cases), mild upper respiratory tract $(7$ cases) and lower urinary tract (6 cases) infections, and one case of pneumonia. A single case of autoantibody-negative subclinical hypothyroidism was registered. No patient developed a serious adverse event.

Nine patients experienced a total of 12 clinical relapses (figure e-1 on the Neurology ${ }^{\circledR}$ Web site at Neurology.org/nn). The mean Expanded Disability
Status Scale (EDSS) score did not change significantly during the 24-month follow-up (EDSS score from 2. 5 at baseline to 2.3 at month 24).

Increase in anti-inflammatory cytokines and decrease in proinflammatory cytokines, chemokines, and chemokine receptors. $\mathrm{PB}$ mRNA levels of the anti-inflammatory cytokines IL-10, IL-27, and TGF- $\beta$ significantly increased at each time point after alemtuzumab treatment compared with baseline. FoxP3 mRNA significantly increased at month 12 and thereafter (figure 1A). mRNA levels of proinflammatory cytokines and transcriptional factors related to the Th17 (IL-1B, IL-6, IL-17A, IL-17F, IL-23, IL-26, TNF- $\alpha$, RORC) and Th1 subset (IL-12, IFN- $\gamma$, Tbet), and of proinflammatory chemokines or chemokine receptors (CCR3, CCR4, CCR5, CCR6, CXCR3, CXCL10, CCL20, VLA4) (figure 1B), significantly decreased at each time point compared with baseline, except for IL-22, which did not decrease at month 18. Overall, the observed increases and decreases in mRNA levels occurred during the first 12 months, and remained at values similar to month 12 thereafter. Interestingly, IL-2, a cytokine that promotes T-cell proliferation, significantly increased at month 18 and 24 (figure $1 B)$. We did not observe any differences in any of the mRNA levels either before or after treatment in the 3 patients who developed autoimmune adverse events compared to the other patients. Unlike what was observed in another group of alemtuzumab-treated patients, ${ }^{35}$ IL-21 decreased after alemtuzumab treatment in all our patients, regardless of the occurrence of autoimmune adverse events. This difference might be related to the difference in the technique used to determine IL-21, i.e., the detection of the protein mRNA in our study or the protein itself with ELISA in the other reports. ${ }^{35}$

Increase in Treg cells percentage and function in the late phase of alemtuzumab treatment follow-up. CD4 + cell percentage in the PBMC rapidly decreased after the first course. At month 6 , it was reduced by $66 \%$ compared to baseline and, although the percentage increased in the following months, it still remained significantly lower than baseline throughout the follow-up (figure 2A). We did not observe any significant changes in the percentage of Th1 or Th17 (single producing or IL-17 and IFN- $\gamma$ coproducing) cells within the $\mathrm{CD} 4+$ fraction at any of the time points (figure $2 \mathrm{~B}$ ); however, the absolute numbers of Th17 and Th1 cells were significantly decreased after alemtuzumab administration (figure e-2). Of interest, a significant increase from baseline of IL-17 CD4+-producing cells, accompanied by IL-2 mRNA increase in the blood, was observed in 6 patients who had a 
Figure 1 mRNA levels in peripheral blood mononuclear cells of patients with multiple sclerosis treated with alemtuzumab
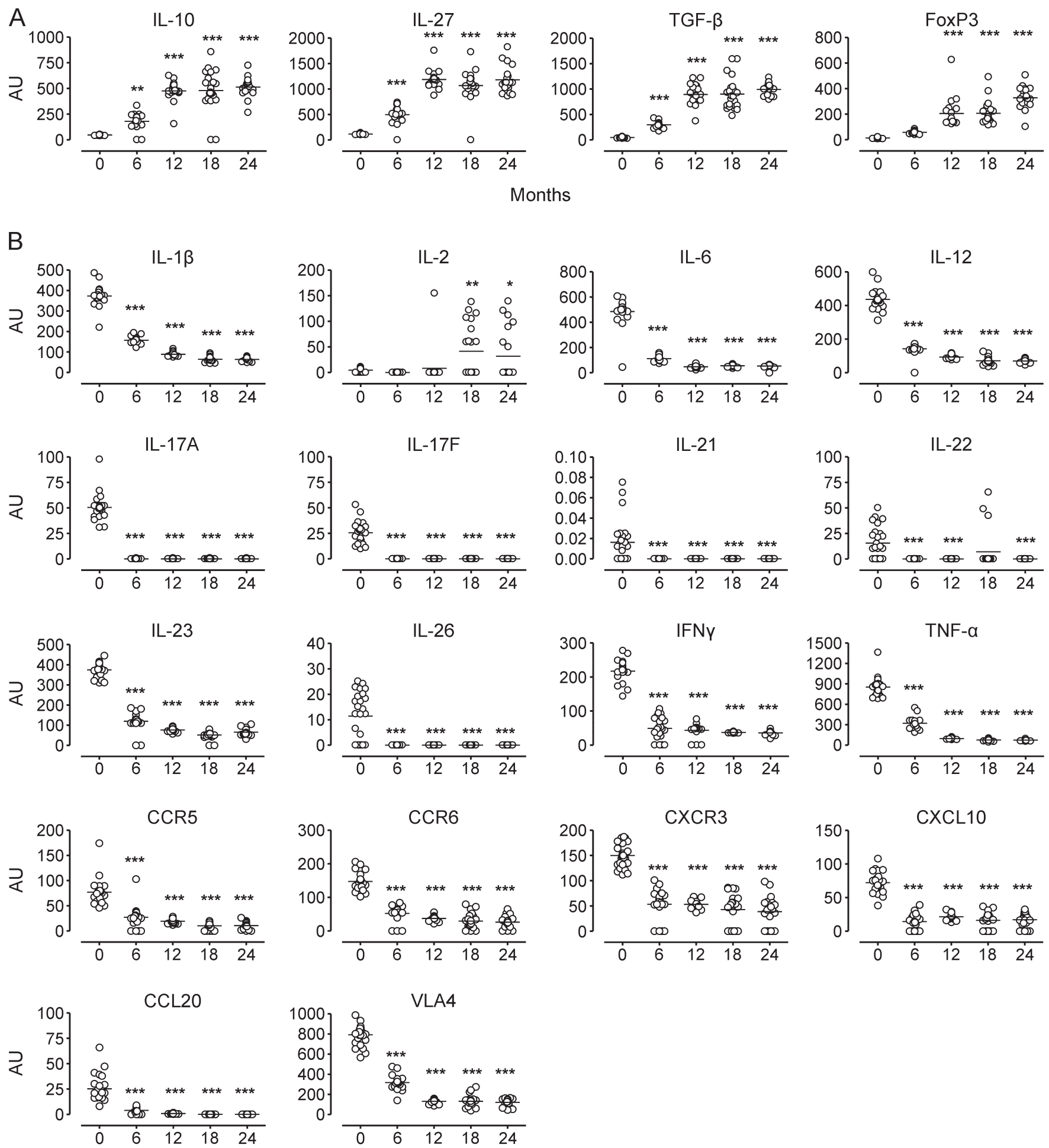

Months

mRNA levels of anti-inflammatory (A) and proinflammatory (B) molecules are presented as arbitrary units (AU) (see Methods) at months 0, 6, 12, 18 , and 24. Horizontal black lines indicate means. Statistical significance (one-way analysis of variance) is calculated with respect to baseline (month 0 ) values, and indicated as $* p<0.05, * * p<0.001, * * * p<0.0001$. CCL = C-C motif ligand; CCR = C-C chemokine receptor; CXCL = C-X-C motif ligand; CXCR = C-X-C chemokine receptor; FoxP3 = forkhead box P3; IFN = interferon; IL = interleukin; TGF = transforming growth factor; TNF = tumor necrosis factor; VLA = very late antigen.

clinical relapse around month 18 (figure 3). A significant increase in $\mathrm{CD} 4+\mathrm{CD} 25^{\text {high }} \mathrm{CD} 127^{\text {low }} \mathrm{FoxP} 3+$ Treg cell percentage was observed at month 24 (figure 2C). To understand if the increase was due to an expansion of the memory Treg cell compartment or to a de novo production of naive Treg cells, we analyzed the expression of CD45RA and CD45RO in the FoxP3 + fraction. We observed 
A

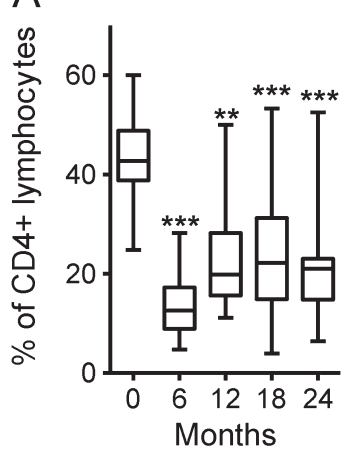

C

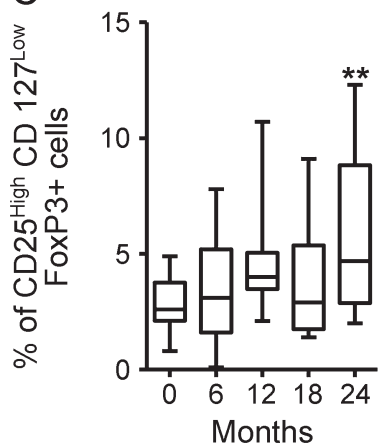

$\mathrm{B}$

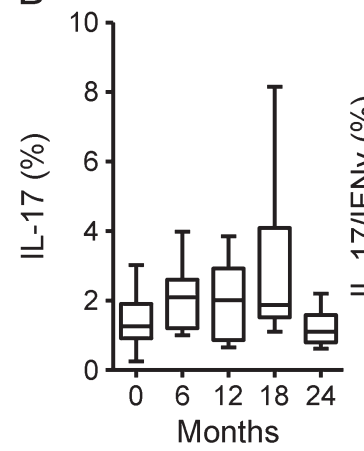

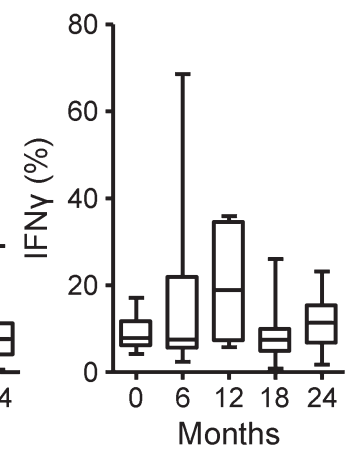

D

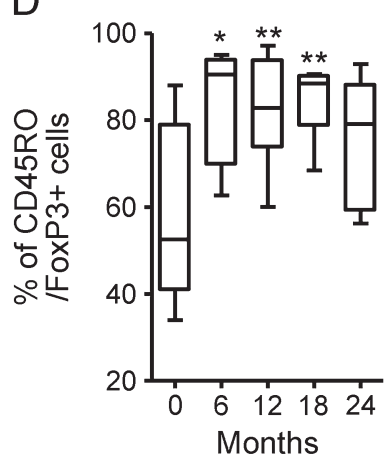

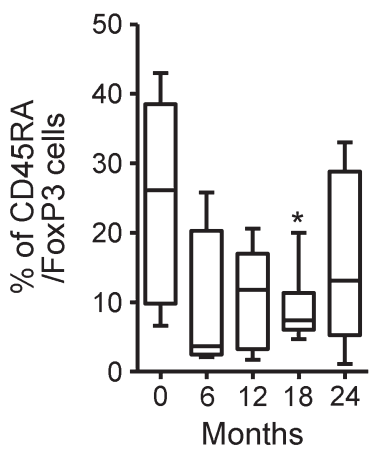

(A) CD4+ lymphocyte percentage. (B) Interleukin (IL)-17, interferon (IFN)- $\gamma$, and IL-17/IFN- $\gamma$-producing cell percentage among the CD4+ fraction. (C) CD4+CD25 high CD127lowforkhead box P3 (FoxP3+) T-regulatory cells lymphocyte percentage among the CD4+ fraction. (D) Percentage of CD4+FoxP3 + cells expressing CD45RO and CD45RA. Statistical significance (one-way analysis of variance) is calculated with respect to baseline (month 0 ) values, and indicated as $* p<0.05$, $* * p<0.001, * * * p<0.0001$.

a significant increase in the percentage of memory CD45RO+CD4+FoxP3+ lymphocytes, accompanied by a relative contraction of the percentage of naive CD45RA+CD4+FoxP3+ lymphocytes.

\begin{tabular}{|ll|}
\hline Figure 3 & $\begin{array}{l}\text { T-helper } 17 \text { cells and interleukin (IL)-2 } \\
\text { mRNA were higher in patients who } \\
\text { relapsed }\end{array}$ \\
\hline
\end{tabular}

A

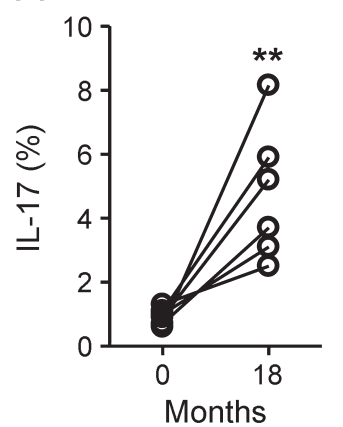

B

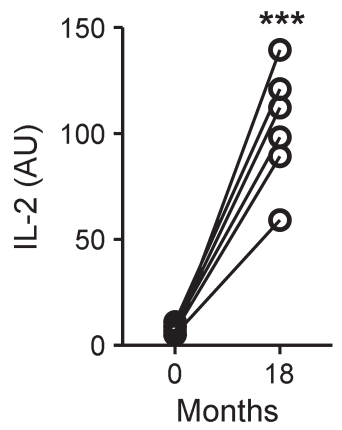

Fluorescence-activated cell sorting analysis of IL-17-producing cell percentage among the CD4+ fraction (A) and mRNA levels of IL-2 (B) at months 0 and 18 in 6 patients with a documented relapse around month $18 . * * p<0.001$, $* * * p<$ 0.0001 , Pearson $t$ test. $A U=$ arbitrary units.
Suppressor function was assessed by measuring the antigen-specific IFN- $\gamma$ and IL-17 production in the PBMC before and after $\mathrm{CD} 25+$ fraction depletion. If the CD25 + T-cell fraction contained cells with regulatory activity, an increase in IFN- $\gamma$ and IL-17 production by $\mathrm{PBMC}^{\mathrm{CD} 25-}$ cells should occur after depletion. At baseline, 33\% of the patients displayed an increase in MBP-specific spots after Treg depletion. This percentage increased slightly to $42 \%$ at month 12 , and further increased to $60 \%$ (significantly compared to baseline) at month 24 (figure 4). This increase in suppressor function was specific for MBP, a CNS antigen, and did not occur for PPD (data not shown).

DISCUSSION Our study suggests that alemtuzumab long-lasting therapeutic effect in MS may involve a shift in the cytokine balance towards inhibition of inflammation associated with a reconstitution of the PB CD4+ T-cell subsets involving the expansion of Treg cells with increased suppressive function.

In agreement with previous studies, ${ }^{5,11}$ we observed a dramatic and early reduction of the CD4+ population in our patients. The reconstitution of CD4+ lymphocytes occurred slowly and 24 
Figure 4 Assessment of T-regulatory cells suppressor activity by interleukin (IL)-17 and interferon (IFN)- $\gamma$ enzyme-linked immunospot

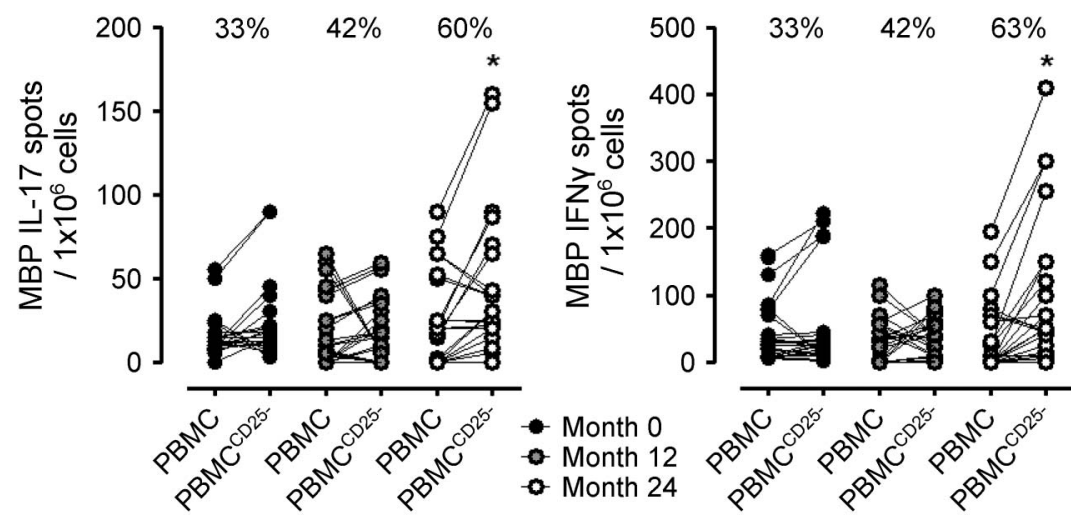

Myelin basic protein (MBP)-specific spots in the peripheral blood mononuclear cells (PBMC) or in PBMC ${ }^{\mathrm{CD} 25-}$ after background subtraction of unstimulated PBMC or PBMCCD25-, respectively. Percentages indicate the percentage of patients displaying an increase in MBP-specific spots in the PBMC ${ }^{C D 25-}$ compared with PBMC. ${ }^{*} p<0.05$, Pearson $t$ test.

months after the first alemtuzumab administration the percentage of $\mathrm{CD} 4+$ cells was still approximately half of the baseline level.

Th1 and Th17 cells are important effectors in the pathogenesis of RRMS, ${ }^{6,8,20,36,37}$ whereas Treg cells counteract their encephalitogenic effect. ${ }^{38}$ The number of Th17 and Th1 cells in the blood and the mRNA transcripts of proinflammatory cytokines and transcription factors related to these subsets decreased at all timepoints after alemtuzumab administration compared to baseline. Analysis of the mRNA levels revealed profound modification after treatment as a significant decrease of chemokine receptors related to Th17 $\left(\mathrm{CCR} 6{ }^{28}{ }^{2} \mathrm{CCR} 4^{27}\right)$ and Th1 cells $\left(\mathrm{CCR} 3{ }^{26}{ }^{26} \mathrm{CCR} 5,{ }^{26} \mathrm{CXCR}^{29}{ }^{29}\right.$ infiltration into the CNS, and of the VLA-4 integrin, which plays a role in T-cell penetration of the BBB, was observed. Two chemokines that are thought to play a role in the pathogenesis of MS, CCL20 and CXCL10, were significantly decreased after treatment as well. CCL20 is secreted both by the epithelial cells of the inflamed BBB that recruits CCR6+ Th17 cells as well as by Th17 themselves and its serum level was found significantly increased in patients with RRMS.30 CXCL10 serum/tissue ratio is increased in MS. ${ }^{29}$ These data suggest that the beneficial effects of alemtuzumab in MS are due to a reduction of both proinflammatory cytokines and T-cell recruitment into the CNS.

IL-27, TGF- $\beta$, and IL-10 mRNA levels increased after 6 and 12 months and exceeded baseline levels up to 24 months after treatment. The dendritic cellderived IL-27 cytokine is an important inhibitor of Th17/Th1 responses. ${ }^{39}$ TGF- $\beta$ and IL-10 increase Treg cell functions; in MS, IL-10 production is decreased prior to relapses and increased during clinical remission. Increase in the mRNA levels of these cytokines suggests that alemtuzumab shifts the balance towards the production of anti-inflammatory cytokines. The mRNA level of FoxP3 was also upregulated in the blood starting from 12 months after alemtuzumab treatment and even increasing after 24 months, suggesting a Treg cell expansion in number and function. Our study has identified a significantly long-lasting posttreatment increase in Treg cell percentage and function, differently from other reports, ${ }^{5,11}$ where the percentage of Treg cells slowly returns to baseline over 12 months postalemtuzumab. At month 24, a significant increase in the $\mathrm{CD} 4+\mathrm{CD} 25^{\text {high }} \mathrm{CD} 127^{\text {low }} \mathrm{FoxP} 3+$ Treg cell percentage in the PBMC was observed. Moreover, we measured a significant increase in MBP-specific suppressive function, suggesting that the expanded Treg cells specifically suppress myelin-induced autoimmune responses. In agreement with Havari et al., ${ }^{40}$ we observed that after alemtuzumab, the percentage of Treg increased, along with an increase of suppressive activity mediated by contact-dependent and contactindependent mechanisms such as IL-2 consumption. IL-2 is required for effector T-cell proliferation and for Treg function and proliferation. However, further studies are needed to understand the meaning of the increase in Treg cell-suppressive function in the late phase of alemtuzumab treatment follow-up.

From this clinical and immunologic study during a 24-month follow-up after alemtuzumab treatment, we can draw the conclusion that alemtuzumab clinical efficacy may be related to its long-term effects on the immune system, bringing about a significant and long-lasting reduction in the production of proinflammatory molecules and an increase in antiinflammatory activity.

In particular, an increase of molecules related to Treg cells was found.

This goes along with the finding of increased Treg suppressor function, which peaked 24 months after alemtuzumab administration, probably indicating a favorable immunoreconstitution. The continuation of this study up to 48 months of follow-up after the first alemtuzumab administration may provide useful clinical information, for example about the possible timing for further courses of this treatment.

\section{AUTHOR CONTRIBUTIONS}

S.D.M., S.R., F.N., L.D., M.C.: design and conceptualization of the study. S.D.M., S.R.: analysis and interpretation of the data. S.D.M., S.R., F.N., L.D., M.C.: drafting the manuscript for intellectual content. S.D.M., S.R., A.C., V.B., E.C., A.V., S.S.-B., M.H., I.A., D.H., P.A., F.N., L.D., M.C.: revising the manuscript for intellectual content. S.D.M., M.C., E.C., A.V., S.S.-B., M.H., I.A., D.H., P.A.: patient enrollment and follow-up.

\section{STUDY FUNDING}

Supported by Genzyme (Bio2009001) and the Federazione Italiana Sclerosi Multipla (FISM, 2011/R/28) 


\section{DISCLOSURE}

S. De Marcanti, S. Rolla, A. Cucci, and V. Bardina report no disclosures. E.E. Cocco serves on scientific advisory boards for Bayer, Biogen, Merck, Novartis, Sanofi-Genzyme, and Teva; received travel support from Biogen, Merck, Bayer, Novartis, Genzyme, and Teva; received speaker fees from Biogen, Merck, Bayer, Novartis, Genzyme, Teva, and Almirall; and received research support from Fondazione Banco di Sardegna funded by Italian Multiple Sclerosis Foundation. A. Vladic, S. SoldoButkovic, M. Habek, and I. Adamec report no disclosures. D. Horakova received travel funding, speaker honoraria, and/or consultant fees from Biogen, Novartis, Merck, Bayer Schering, and Teva; is an associate editor for BMC Neurology; and received research support from Biogen and Czech Ministries of Education and Health. P. Annovazzi served on the scientific advisory board for Merck Serono, Novartis, Biogen, and Genzyme, and received speaker honoraria from Biogen, Genzyme, Novartis, and Teva. F. Novelli received research support from Fondazione Italiana Sclerosi Multipla. L. Durelli and M. Clerico report no disclosures. Go to Neurology.org/nn for full disclosure forms.

Received September 14, 2015. Accepted in final form October 30, 2015.

\section{REFERENCES}

1. Hartung HP, Aktas O, Boyko AN. Alemtuzumab: a new therapy for active relapsing-remitting multiple sclerosis. Mult Scler 2015;21:22-34.

2. Keating MJ, Flinn I, Jain V, et al. Therapeutic role of alemtuzumab (Campath-1H) in patients who have failed fludarabine: results of a large international study. Blood 2002;10:3554-3561.

3. Cohen JA, Coles AJ, Arnold DL, et al. Alemtuzumab versus interferon beta 1a as first-line treatment for patients with relapsing-remitting multiple sclerosis: a randomised controlled phase 3 trial. Lancet 2012;380:1819-1828.

4. Coles AJ, Twyman CL, Arnold DL, et al. Alemtuzumab for patients with relapsing multiple sclerosis after diseasemodifying therapy: a randomised controlled phase 3 trial. Lancet 2012;380:1829-1839.

5. Cox AL, Thompson SA, Jones JL, et al. Lymphocyte homeostasis following therapeutic lymphocyte depletion in multiple sclerosis. Eur J Immunol 2005;11:3332-3342.

6. Kebir H, Ifergan I, Alvarez JI, et al. Preferential recruitment of interferon-gamma-expressing TH17 cells in multiple sclerosis. Ann Neurol 2009;66:390-402.

7. Bettelli E, Oukka M, Kuchroo VK. T(H)-17 cells in the circle of immunity and autoimmunity. Nat Immunol 2007;8:345-350.

8. Durelli L, Conti L, Clerico M, et al. T-helper 17 cells expand in multiple sclerosis and are inhibited by interferon-beta. Ann Neurol 2009;65:499-509.

9. Kebir H, Kreymborg K, Ifergan I, et al. Human TH17 lymphocytes promote blood-brain barrier disruption and central nervous system inflammation. Nat Med 2007;13:1173-1175.

10. Hill-Cawthorne GA, Button T, Tuohy O, et al. Long term lymphocyte reconstitution after alemtuzumab treatment of multiple sclerosis. J Neurol Neurosurg Psychiatry 2012; 83:298-304.

11. Zhang X, Tao Y, Chopra M, et al. Differential reconstitution of $\mathrm{T}$ cell subsets following immunodepleting treatment with alemtuzumab (anti-CD52 monoclonal antibody) in patients with relapsing-remitting multiple sclerosis. J Immunol 2013;191:5867-5874.

12. McDonald WI, Compston A, Edan G, et al. Recommended diagnostic criteria for multiple sclerosis: guidelines from the International Panel on the diagnosis of multiple sclerosis. Ann Neurol 2001;50:121-127.
13. Cucci A, Barbero P, Clerico M, et al. Pro-inflammatory cytokine and chemokine mRNA blood level in multiple sclerosis is related to treatment response and interferonbeta dose. J Neuroimmunol 2010;226:150-157.

14. Romme Christensen J, Börnsen L, Hesse D, et al. Cellular sources of dysregulated cytokines in relapsing-remitting multiple sclerosis. J Neuroinflammation 2012;14:9-215.

15. Milo R. The efficacy and safety of daclizumab and its potential role in the treatment of multiple sclerosis. Ther Adv Neurol Disord 2014;7:7-21.

16. Tao Y, Zhang X, Chopra M, et al. The role of endogenous IFN- $\beta$ in the regulation of Th17 responses in patients with relapsing-remitting multiple sclerosis. J Immunol 2014;192:5610-5617.

17. Jana M, Mondal S, Jana A, Pahan K. Interleukin-12 (IL12), but not IL-23, induces the expression of IL-7 in microglia and macrophages: implications for multiple sclerosis. Immunology 2014;141:549-563.

18. Jadidi-Niaragh F, Mirshafiey A. Th17 cell, the new player of neuroinflammatory process in multiple sclerosis. Scand J Immunol 2011;74:1-13.

19. Tzartos JS, Craner MJ, Friese MA, et al. IL-21 and IL-21 receptor expression in lymphocytes and neurons in multiple sclerosis brain. Am J Pathol 2011;178:794-802.

20. Rolla S, Bardina V, De Mercanti S, et al. Th22 cells are expanded in multiple sclerosis and are resistant to IFN- $\beta$. J Leukoc Biol 2014;96:1155-1164.

21. Shajarian M, Alsahebfosoul F, Etemadifar M, et al. IL-23 Plasma level measurement in relapsing remitting multiple sclerosis (RRMS) patients compared to healthy subjects. Immunol Invest 2014;1:1-9.

22. Vojdani A, Lambert J. The role of Th17 in neuroimmune disorders: target for CAM therapy: part I. Evid Based Complement Alternat Med 2011;9:27-294.

23. MK Racke, Yang Y, Lovett-Racke AE. Is t-bet a potential therapeutic target in multiple sclerosis? J Interferon Cytokine Res 2014;34:623-632.

24. Xiao S, Yosef N, Yang J, et al. Small-molecule ROR $\gamma \mathrm{t}$ antagonists inhibit $\mathrm{T}$ helper 17 cell transcriptional network by divergent mechanisms. Immunity 2014;40:477-489.

25. Farhadi N, Oryan S, Nabiuni M. Serum levels of melatonin and cytokines in multiple sclerosis. Biomed J 2014; 37:90-92.

26. Simpson J, Rezaie P, Newcombe J, Cuzner ML, Male D, Woodroofe MN. Expression of the beta-chemokine receptors CCR2, CCR3 and CCR5 in multiple sclerosis central nervous system tissue. J Neuroimmunol 2000;108:192-200.

27. Mony JT, Khorooshi R, Owens T. Chemokine receptor expression by inflammatory $\mathrm{T}$ cells in EAE. Front Cell Neurosci 2014;4:8-187.

28. Reboldi A, Coisne C, Baumjohann D, et al. C-C chemokine receptor 6-regulated entry of TH-17 cells into the CNS through the choroid plexus is required for the initiation of EAE. Nat Immunol 2009;10:514-523.

29. Vazirinejad R, Ahmadi Z, Kazemi Arababadi M, Hassanshahi G, Kennedy D. The biological functions, structure and sources of CXCL10 and its outstanding part in the pathophysiology of multiple sclerosis. Neuroimmunomodulation 2014;21:322-330.

30. Jafarzadeh A, Bagherzadeh S, Ebrahimi HA, et al. Higher circulating levels of chemokine CCL20 in patients with multiple sclerosis: evaluation of the influences of chemokine gene polymorphism, gender, treatment and disease pattern. J Mol Neurosci 2014;53:500-505. 
31. Steinman L. Immunology of relapse and remission in multiple sclerosis. Annu Rev Immunol 2014;32:257-281.

32. Shaygannejad V, Montazeri S, Jamshidian A, et al. Correlation of midkine serum level with pro- and antiinflammatory cytokines in multiple sclerosis. Iran J Immunol 2014;11:134-138.

33. Babaloo Z, Yeganeh RK, Farhoodi M, Baradaran B, Bonyadi M, Aghebati L. Increased IL-17A but decreased IL-27 serum levels in patients with multiple sclerosis. Iran J Immunol 2013;10:47-54.

34. Edström M, Mellergård J, Mjösberg J, et al. Suppressive populations in blood: transcriptional characteristics of CD4 + T cells in multiple sclerosis: relative lack of suppressive populations in blood. Mult Scler 2011;17:57-66.

35. Costelloe L, Jones J, Coles A. Secondary autoimmune diseases following alemtuzumab therapy for multiple sclerosis. Expert Rev Neurother 2012;12:335-341.
36. Sospedra M, Martin R. Immunology of multiple sclerosis. Annu Rev Immunol 2005;23:683-747.

37. Li Y, Wang H, Long Y, Lu Z, Hu X. Increased memory Th17 cells in patients with neuromyelitis optica and multiple sclerosis. J Neuroimmunol 2011;234:155-160.

38. Viglietta V, Baecher-Allan C, Weiner HL, Hafler DA. Loss of functional suppression by $\mathrm{D} 4+\mathrm{CD} 25+$ regulatory $\mathrm{T}$ cells in patients with multiple sclerosis. J Exp Med 2004;199:971-979.

39. Chong WP, Horai R, Mattapallil MJ, et al. IL-27p28 inhibits central nervous system autoimmunity by concurrently antagonizing Th1 and Th17 responses. J Autoimmun 2014; 50:12-22.

40. Havari E, Turner MJ, Campos-Rivera J, et al. Impact of alemtuzumab treatment on the survival and function of human regulatory $\mathrm{T}$ cells in vitro. Immunology 2014;1: 123-131. 


\title{
Neurology \\ Neuroimmunology \& Neuroinflammation
}

\author{
Alemtuzumab long-term immunologic effect: Treg suppressor function increases up to \\ 24 months \\ Stefania De Mercanti, Simona Rolla, Angele Cucci, et al. \\ Neurol Neuroimmunol Neuroinflamm 2016;3; \\ DOI 10.1212/NXI.0000000000000194
}

This information is current as of January 21, 2016

\section{Updated Information \& \\ Services}

Supplementary Material

References

Citations

Subspecialty Collections

Permissions \& Licensing

Reprints including high resolution figures, can be found at:

http://nn.neurology.org/content/3/1/e194.full.html

Supplementary material can be found at:

http://nn.neurology.org/content/suppl/2016/01/21/3.1.e194.DC1

http://nn.neurology.org/content/suppl/2016/01/21/3.1.e194.DC2

This article cites 40 articles, 4 of which you can access for free at: http://nn.neurology.org/content/3/1/e194.full.html\#\#ref-list-1

This article has been cited by 3 HighWire-hosted articles: http://nn.neurology.org/content/3/1/e194.full.html\#\#otherarticles

This article, along with others on similar topics, appears in the following collection(s):

Multiple sclerosis

http://nn.neurology.org//cgi/collection/multiple_sclerosis

Information about reproducing this article in parts (figures,tables) or in its entirety can be found online at:

http://nn.neurology.org/misc/about.xhtml\#permissions

Information about ordering reprints can be found online: http://nn.neurology.org/misc/addir.xhtml\#reprintsus

Neurol Neuroimmunol Neuroinflamm is an official journal of the American Academy of Neurology.

Published since April 2014, it is an open-access, online-only, continuous publication journal. Copyright $\odot$ 2016 American Academy of Neurology. All rights reserved. Online ISSN: 2332-7812.

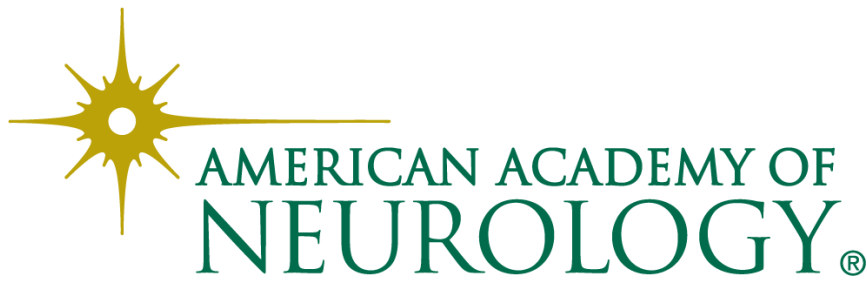

